\title{
The relation of Hereditery Multiple Exostoses and trace elements
}

\author{
Fatma Ates Alkan ${ }^{1}$, Dilek Duzgun Ergun ${ }^{1}$, Nural Pastaci Ozsobaci ${ }^{1}$, Duygu Tarhan ${ }^{1}$, \\ Bahar Ozturk Kurt ${ }^{1}$, Muharrem Babacan ${ }^{2}$, Umit Bora Barutcu ${ }^{1}$
}

\begin{abstract}
Introduction: Hereditary multiple exostoses (HME) is a rarely autosomal dominant bone tumoral disorder; which is characterized by abnormal ossification especially at long bones. The common symptoms are bone pain, joint movement limitation, malign degeneration, vessel and neuron impression and asymmetry of extremities.

Material and Methods: The association of a group of trace elements of the HME patient was analysed at the Department of Biophysics. A 26-year-old male patient (weight $60 \mathrm{~kg}$, height $170 \mathrm{~cm}$ ) who admitted to Department of Orthopaedics Out-patient Clinic at Cerrahpasa Medical Faculty in July 2013 had been suffering from bone pain and prominences in different parts of his body for 20 years. Other individuals diagnosed with HME were reported in his family history.

Results: When the values of serum Ca (134.5 ppm), P (173.3 ppm), Fe (1.104 ppm), Se (1.119 ppm) and as $(0.647 \mathrm{ppm})$ levels in patient were compared with reference ranges, all these elements had showed higher values. However, Zn $(0.562 \mathrm{ppm})$ levels had a lower value than reference ranges. Residual trace elements that were determined in patient were found in physiological ranges. Ni level was too low to be measured

Conclusion: Until this time there has been no investigation about the association of HME and trace elements. The level of trace elements that play crucial roles in all systems especially bone and renal metabolism should be kept in mind in evaluation of HME patients. For this purpose, familial and environmental trace element level determination would be one of our projects in this study.
\end{abstract}

Key words: Hereditary Multiple Exostoses, Osteochondroma, Trace element

Introduction

Hereditary multiple exostoses (HME) is an autosomal dominant bone tumoral disorder; which is characterized by abnormal ossification especially from the metaphysis of long bones [1, 2]. HME, which includes growth retardation and osteochondromas; is a rarely seen disorder. Onset of the disease is from early childhood (2-3 years) to puberty, with $40 \%$ of patients were affected before 10 years of age. The lesions can be present at birth and continue to appear and grow throughout childhood and into puberty. Nevertheless, the diagnosis of HME at birth has been rarely described [3]. Bones formed via intramembranous formation are not involved. The prevalence of HME has been estimated to be at least $1 / 50000$ in the general population, and penetrance is estimated to be $96 \%$. Most published instances of non-penetrance have occurred in females.
Osteochondromas may cause complications, including osseous and cosmetic deformities, fracture, bursa formation and impingement on adjacent structures (tendons, nerves, vessels) and malignant transformation. Osteochondromas that are located at pelvis, knee and shoulder are prone to malign transformation [4, $5,6]$. Growing of osteochondromas cause defects around perichondrium; this is called as Ranvier cycle and covers epiphyseal plaque. This perichondrial defect allow the growing of cartilage to sides and it binds to growing plaque with 90 degree angle and generate the typical appearance of osteochondroma. The common symptoms are bone pain, joint movement limitation, malign degeneration, vessel and neuron impression, asymmetry of extremities [7]. 


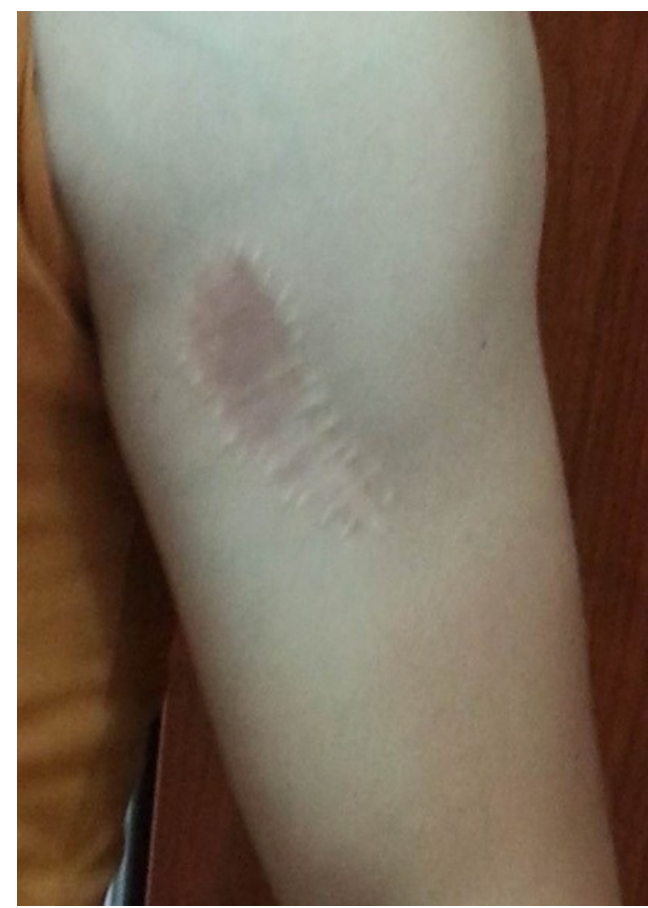

Picture 1: HME patient had operations on his left arm

HME is genetically heterogeneous, and three loci have been identified so far: EXT1, on chromosome 8q23-q24; EXT2, on 11p11-p12; and EXT3, on the short arm of chromosome 19 [8, 9, 10, 11]. Loss of heterozygosity at the EXT1, EXT2 and EXT3 loci has been observed among patients with EXT-related and unrelated chondrosarcomas, suggesting that EXT genes are tumour suppressors in chondrosarcomas $[12,13,14]$.

Trace elements are cofactors in enzymatic reactions. Deficiency of trace elements (such as zinc or selenium) and excessive of potentially harmful trace elements (such as lead or arsenic) are both known to have adverse consequences in general population $[15,16,17]$. Despite the excess number of studies, we have not encountered studies with HME and trace elements. In present study, we aim to evaluate the association of some trace elements in the patient with HME disease who admitted to Orthopedics Out-patient Clinic at Cerrahpasa Medical Faculty.

\section{Material and Methods}

A 26-year-old male patient (weight $60 \mathrm{~kg}$, height $170 \mathrm{~cm}$ ) who admitted to Orthopaedics Outpatient Clinic at Cerrahpasa Medical Faculty had been suffering from bone pain and prominences in different parts of his body for 20 years in July 2013. Other individuals diagnosed with HME were reported in his family history.

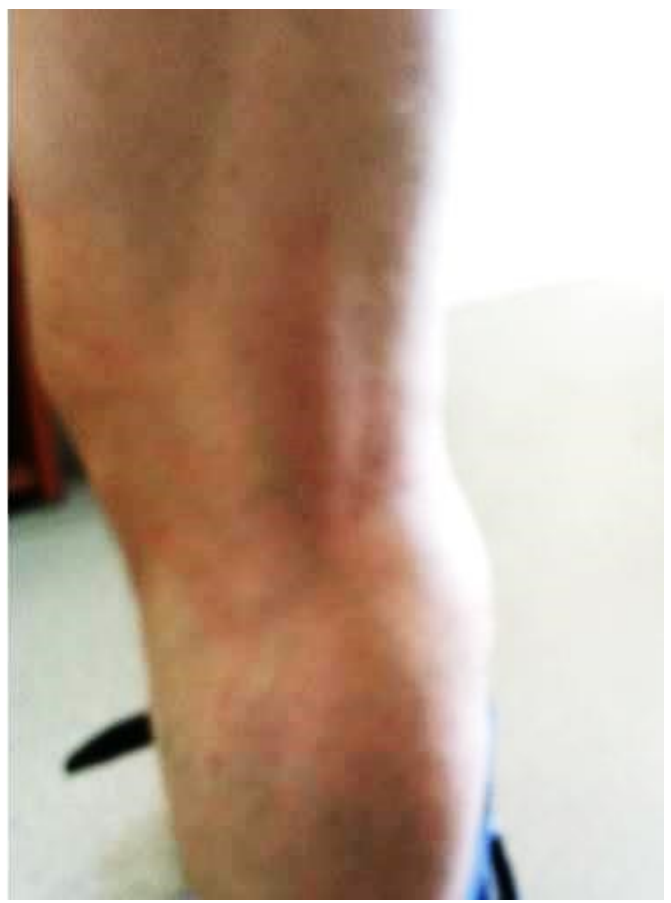

Picture 2: Swelling located at left leg resulted from osteochondromas

The diagnosis of HME in postoperative pathology report revealed that our patient had been operated on his left arm, elbow and wrist. Difficulties in movement were found out because of these deformities [Picture 1]. In addition, a swelling on right leg was visible [Picture 2]. Left proximal humerus and meta-diaphysis of left tibia were hypertrophic in radiological examination with new bone formations.

The concentrations of calcium, phosphor, chrome, iron, copper, magnesium, manganese, selenium, zinc, boron, silicon, nickel, arsenic and cobalt elements in serum were analysed by Inductively Coupled Plasma Optical Emission Spectrometry (ICP-OES - Thermo - iCAP 6000) in Trace Element Laboratory at Biophysics Department.

Results

When the serum values of $\mathrm{Ca}(134.5 \mathrm{ppm})$, P (173.3 ppm), Fe (1.104 ppm), Se (1.119 ppm) and as $(0.647 \mathrm{ppm})$ levels in patient were compared with reference ranges, all these elements showed higher values. However, Zn (0.562 ppm) levels had a lower value than reference ranges. Residual trace elements that were determined in patient were found in physiological ranges. Ni level was too low to be measured [Table 1] 
Table 1. Trace element levels of patient with HME

\begin{tabular}{ccc}
\hline $\begin{array}{c}\text { Concentrations } \\
(\mathbf{p p m})\end{array}$ & $\begin{array}{c}\text { Results } \\
(\mathbf{p p m})\end{array}$ & $\begin{array}{c}\text { References } \\
(\mathbf{p p m})\end{array}$ \\
\hline $\mathbf{C a}$ & $134.5(\uparrow)$ & $85-115$ \\
$\mathbf{P}$ & $173.3(\uparrow)$ & $25-45$ \\
$\mathbf{C r}$ & 0.011 & $0.05-0.5$ \\
$\mathbf{F e}$ & $1.104(\uparrow)$ & $0.9-1.2$ \\
$\mathbf{C u}$ & 1.046 & $1-2$ \\
$\mathbf{M g}$ & 27.90 & $17-30$ \\
$\mathbf{M n}$ & 0.022 & $1.9-5.8$ \\
$\mathbf{S e}$ & $1.119(\uparrow)$ & $0.0005-0.0015$ \\
$\mathbf{Z n}$ & $0.562(\downarrow)$ & $0.7-1.2$ \\
$\mathbf{B}$ & 0.05 & $0.033-0.191$ \\
$\mathbf{S i}$ & 0.670 & $0.4-10$ \\
$\mathbf{N i}$ & $(-)$ & $0.0510^{-3}-1.110^{-3}$ \\
$\mathbf{A s}$ & $0.647(\uparrow)$ & $0.001-0.004$ \\
\hline
\end{tabular}

$(\uparrow)$ : higher than reference values, $(\downarrow)$ : lower than reference values, (-): too low to be detectable

\section{Discussion}

HME is a genetically heterogeneous disease located at the locus for the genes of $\mathrm{EXT}_{1}$ and $\mathrm{EXT}_{2}$. Pannier $\mathrm{S}$ et al. reported that EXT1 and EXT2 may have tumour suppressing activity. Some studies have concluded that mutations in either the EXT1 or the EXT2 genes are responsible for most cases of multiple exostoses. However in Caucasian and Japanese patients, mutations were detected in EXT1 genes more than in EXT2 genes. Premature terminations of the EXT proteins were caused by most of the mutations in the two genes $[12,18]$.

After performing sequencing analysis in some families, it was not possible to detect the disease-causing mutation. The presence of a third gene (EXT3 gene) that is a minor disease locus for HME could be a possibility [14, 19, 20]. Symptomatic lesions are because of complications, which include fracture, osseous and cosmetic deformities, impingement on adjacent structures (nerves, vessels and tendons), bursa formation and malignant complications such as spinal cord compression resulting from HME. Number of osteochondromas of each patient may change significantly, even within families. The osteochondromas may range from a few lesions to a thousand. The exibility cause of clinical variability could not be still explained, although various mutations are identified in $\operatorname{HME}[1,6,21]$.
Trace elements have an important role in skeletal and muscular system, nerve transmission, and many biological processes such as kidney metabolism. In this study, we analysed that the serum selenium, calcium, iron, arsenic and phosphorus values in the patient were higher than normal values. Selenium, arsenic and phosphorus and particularly calcium and iron elements, playing a role in bone metabolism, were found to be high in our study. We think that the evaluation of patients with HME should be taken into consideration by means of the level of trace elements that play crucial role on the whole system particularly in bone and kidney metabolism. We suggest that trace element levels have to be considered for diagnosis and treatment of HME patients. In near future, our main goal is to determine familial and environmental trace element level.

Acknowledgments: The authors do not have any financial interest in the companies whose materials are included in this article

Conflict of Interest: The authors declare no potential conflicts of interest with respect to the research, authorship, and/or publication of this article.

\section{References}

1. Vanhoenacker FM, Van Hul W, Wuyts W, Willems PJ, De Schepper AM. Hereditary multiple exostoses: from genetics to clinical syndrome and complications. European journal of radiology. 2001;40(3):208-17.

2. Fisher TJ, Williams N, Morris L, Cundy PJ. Metachondromatosis: more than just multiple osteochondromas. Journal of children's orthopaedics. $2013 ; 7(6): 455-64$

3. Porter DE, Emerton ME, Villanueva-Lopez F, Simpson AH. Clinical and radiographic analysis of osteochondromas and growth disturbance in hereditary multiple exostoses. Journal of pediatric orthopedics. 2000;20(2):246-50.

4. Anantharamaiah H, Kalyani R, Kumar MLH, P VM. Secondary Chondrosarcoma of the Lumbosacral Region: Are any Bones Spared in the Multiple Hereditary Exostoses? Journal of clinical and diagnostic research : JCDR. 2012;6(10):1778-80.

5. Bovee JV. Multiple osteochondromas. Orphanet journal of rare diseases. 2008;3:3.

6. Murphey MD, Choi JJ, Kransdorf MJ, Flemming DJ, Gannon FH. Imaging of osteochondroma: variants and complications with radiologic-pathologic correlation. Radiographics : a review publication of the Radiological Society of North America, Inc. 2000;20(5):1407-34. 
7. Silve C, Juppner H. Ollier disease. Orphanet journal of rare diseases. 2006;1:37.

8. Jennes I, Pedrini E, Zuntini M, Mordenti M, Balkassmi $\mathrm{S}$, Asteggiano $\mathrm{CG}$, et al. Multiple osteochondromas: mutation update and description of the multiple osteochondromas mutation database (MOdb). Human mutation. 2009;30(12):1620-7.

9. R K, K P, B G, Naseer BS, Ds K. Multiple heriditary exostoses in a family for three generation of Indian origin with review of literature. Journal of clinical and diagnostic research : JCDR. 2014;8(10):LD01-3.

10. Le Merrer M, Legeai-Mallet L, Jeannin PM, Horsthemke B, Schinzel A, Plauchu H, et al. A gene for hereditary multiple exostoses maps to chromosome 19p. Human molecular genetics. 1994;3(5):717-22.

11. Seki H, Kubota T, Ikegawa S, Haga N, Fujioka F, Ohzeki S, et al. Mutation frequencies of EXT1 and EXT2 in 43 Japanese families with hereditary multiple exostoses. American journal of medical genetics. 2001;99(1):59-62.

12. Pannier S, Legeai-Mallet L. Hereditary multiple exostoses and enchondromatosis. Best practice \& research Clinical rheumatology. 2008;22(1):45-54.

13. Carroll KL, Yandow SM, Ward K, Carey JC. Clinical correlation to genetic variations of hereditary multiple exostosis. Journal of pediatric orthopedics. 1999;19(6):785-91.

14. Zhao WQ, Song SJ, Wei Q, Qiao J. [A new EXT2 mutation in a Chinese family with hereditary multiple exostoses]. Zhonghua yi xue yi chuan xue za zhi $=$ Zhonghua yixue yichuanxue zazhi $=$ Chinese journal of medical genetics. 2009;26(3):241-4.
15. Tonelli M, Wiebe N, Hemmelgarn B, Klarenbach S, Field C, Manns B, et al. Trace elements in hemodialysis patients: a systematic review and meta-analysis. BMC medicine. 2009;7:25.

16. Shrimpton R, Gross R, Darnton-Hill I, Young M. Zinc deficiency: what are the most appropriate interventions? Bmj. 2005;330(7487):347-9..

17. Pasko DA, Churchwell MD, Btaiche IF, Jain JC, Mueller BA, Renal Replacement Therapy Kinetics Study G. Continuous venovenous hemodiafiltration trace element clearance in pediatric patients: a case series. Pediatric nephrology. 2009;24(4):807-13.

18. Seki H, Kubota T, Ikegawa S, Haga N, Fujioka F, Ohzeki S, et al. Mutation frequencies of EXT1 and EXT2 in 43 Japanese families with hereditary multiple exostoses. American journal of medical genetics. 2001;99(1):59-62.

19. Signori E, Massi E, Matera MG, Poscente M, Gravina $\mathrm{C}$, Falcone $\mathrm{G}$, et al. A combined analytical approach reveals novel EXT1/2 gene mutations in a large cohort of Italian multiple osteochondromas patients. Genes, chromosomes \& cancer. 2007;46(5):470-7.

20. Mehta M, White LM, Knapp T, Kandel RA, Wunder JS, Bell RS. MR imaging of symptomatic osteochondromas with pathological correlation. Skeletal radiology. 1998;27(8):427-33.

21. Eschelman DJ, Gardiner GA, Jr., Deely DM. Osteochondroma: an unusual cause of vascular disease in young adults. Journal of vascular and interventional radiology : JVIR. 1995;6(4):605-13.

Copyright (C) 2014 The Author(s); This is an open-access article distributed under the terms of the Creative Commons Attribution License (http://creativecommons.org/licenses/by/4.0), which permits unrestricted use, distribution, and reproduction in any medium, provided the original work is properly cited. 